\title{
Camelliol C inhibits viability, migration, and invasion of human cervical cancer cells via induction of apoptosis, G2/M cell cycle arrest, and blocking of PI3K/AKT signalling pathway
}

$\mathrm{Na}$ An, Feng Liu

Department of Obstetrics and Gynaecology, Shengli Oilfield Central Hospital, Dongying, Shandong, China

Submitted: 7 April 2020

Accepted: 24 April 2020

Arch Med Sci

DOI: https://doi.org/10.5114/aoms.2020.95964

Copyright $\odot 2020$ Termedia \& Banach

\section{Abstract}

Introduction: Cervical cancer is a devastating cancer and is currently ranked as the fourth most prevalent type of cancer in the world. The lack of efficacious chemotherapy forms a bottleneck in the treatment of cervical cancer. This study was therefore undertaken to evaluate the anticancer effects of camelliol $C$ against human cervical cancer cells.

Material and methods: Normal cell line (NCEC) and cervical cancer cell lines (Csdki, HeLa, C33A, and siHa) were used in this study. Cell viability was determined by MTT assay, and apoptosis was detected by DAPI and annexin V/ PI staining. Cell cycle analysis, ROS, and MMP levels were examined by flow cytometry. Cell migration and invasion was monitored by transwell assays. Results: The results showed that camelliol $\mathrm{C}$ inhibits the proliferation of all the human cervical cancer cell lines with $\mathrm{IC}_{50}$ ranging from 10 to $20 \mu \mathrm{M}$. However, comparatively low antiproliferative effects were observed on the normal cells. Investigation of the underlying mechanisms showed that camelliol C induces apoptosis in HeLa cancer cells. Camelliol C-triggered apoptosis was also linked with cleavage of caspase- 3 and -9, and PARP. Additionally, the Bax protein levels were increased and those of $\mathrm{Bcl}-2$ were decreased. Transwell assays showed that camelliol $C$ suppresses the migration and invasion of the HeLa cervical cancer cells. Additionally, camelliol C also blocked the PI3K/AT signalling cascade dose dependently.

Conclusions: Camelliol C may prove beneficial in the treatment of cervical cancer.

Key words: cervical cancer, apoptosis, cell cycle, camelliol C, proliferation.

\author{
Corresponding author: \\ Feng Liu \\ Department of Obstetrics \\ and Gynaecology \\ Shengli Oilfield \\ Central Hospital \\ 31 Jinan Road \\ Dongying \\ Shandong 257000, China \\ Phone/fax: +86 546855 \\ 1381 \\ E-mail: \\ 15254690177@163.com
}

\section{Introduction}

Globally, cervical cancer is responsible for a significant number of human mortalities. Approximately 0.54 million new cervical cancer cases and 0.25 million cervical cancer-related deaths were reported in 2012 [1]. Cervical cancer is also known as the 'disease of disparity' owing to its inconsistent incidence in high- and low-income countries [2]. As per the estimates, cervical is the fourth most prevalent type of cancer worldwide, and it is believed that its incidence will increase significantly in the next decade [3]. Treatment of cervical cancer generally involves surgery and 
subsequent chemotherapy [4]. Nonetheless, the currently used chemotherapy has adverse effects and is less efficacious [5]. Therefore, the development of cervical cancer chemotherapy with no or negligible side effects is needed. Triterpenes constitute a vast and diverse group of chemical scaffolds generally synthesised by plants [6]. However, some bacteria have also been reported to biosynthesise simple triterpenes, such as hopene [7]. Approximately 20,000 triterpenes have been discovered so far, and many more await discovery. Despite the remarkable commercial applicability of triterpenes, the majority of the natural triterpenoids remain largely untapped [8]. Triterpenes have shown extraordinary potential to be used as drugs for the management of diseases as severe as cancer [9]. Camelliol $C$ is an important triterpenoid [10]. The anticancer activity of camelliol $C$ has not been explored against human cervical cancer cells.

This study was therefore undertaken to investigate the anticancer effects of camelliol $C$ against human cervical cancer cells and to decipher the underlying molecular mechanisms.

\section{Material and methods}

\section{Cell lines and culture conditions}

The normal NCEC line and cervical cancer cell lines (Csdki, HeLa, C33A, and siHa) were purchased from ATCC, USA and cultured in Dulbecco's modified Eagle medium (DMEM, Gibco, USA) medium with $10 \% \mathrm{FBS}$ at $37^{\circ} \mathrm{C}$ in a humidified atmosphere of $5 \% \mathrm{CO}_{2}$.

\section{Cell viability assay}

MTT assay was performed in order to determine the proliferation of normal and cervical cancer cells after being treated with different doses of camelliol $C$ in a 96-well plate. The treatments were applied for $24 \mathrm{~h}$ at $37^{\circ} \mathrm{C}$. After $24 \mathrm{~h}$, the MTT reagent was added to the samples and incubation at $37^{\circ} \mathrm{C}$ was prolonged for a further $4 \mathrm{~h}$. The formazan product thus formed was suspended using the DMSO solution. The samples were red for the absorbance measurements at $450 \mathrm{~nm}$. The $\mathrm{OD}_{450}$ values were used for inferring the proliferation rates of the culture samples.

\section{DAPI staining assay}

To examine the cervical cancer cell apoptosis after their treatment with $0,5,10$, or $20 \mu \mathrm{M}$ camelliol $\mathrm{C}$ in six-well plates at $37^{\circ} \mathrm{C}$ for $24 \mathrm{~h}$, the harvesting of cancer cells was performed through the centrifugation at $5000 \mathrm{rpm}$. The cells were than subjected to staining with DAPI for $10 \mathrm{~min}$. The cells collected were fixed with methanol after being washed with PBS buffer. Afterwards, the cells were examined for the fluorescence measurements using a fluorescence microscope.

\section{Annexin V-FITC/PI staining}

The HeLa cells were cultured in six-well plates at a density of $3 \times 10^{5}$ cells per well, as described previously [11]. The cells were then incubated for $24 \mathrm{~h}$ and treated with different doses of camelliol $\mathrm{C}$ for $48 \mathrm{~h}$. The cells were then collected by trypsinisation. Subsequently, these cells were stained with Annexin V-FITC and PI for 25 min in the dark at $37^{\circ} \mathrm{C}$. Finally, a Beckman Coulter EPICS-XL flow cytometer was used for the determination of the percentage of apoptotic cells.

\section{Cell cycle analysis}

After treatment with $0,5,10$, or $20 \mu \mathrm{M}$ camelliol $\mathrm{C}$ in 12 -well plates at $37^{\circ} \mathrm{C}$ for $24 \mathrm{~h}$, the cell cultures were centrifuged, and the harvested cells were fixed with $4 \%$ formaldehyde. The cells were mixed with propidium iodide solution. Following this, a flow cytometer was used to investigate the phase distribution of the cancer cells.

\section{Migration and invasion assay}

A transwell chamber without or with Matrigel coating was used to assess, respectively, the migration and invasion of transfected cervical cancer cells. Briefly, $100 \mu \mathrm{l}$ of cell culture containing 6000 cells was added to the upper chamber of the transwell, and lower chamber was given $750 \mu$ of DMEM medium supplemented with $10 \%$ FBS. After $48 \mathrm{~h}$ incubation at $37^{\circ} \mathrm{C} / 5 \% \mathrm{CO}_{2}$, cells from the surface of membrane's upper side were removed carefully with cotton swabs while those that stuck to the lower side of membrane were fixed with $70 \%$ ethyl alcohol and stained with $0.1 \%$ crystal violet. A light microscope $(\times 100)$ was used for visualisation of cells, and photographs were taken. At least seven random fields were used for the counting of migratory or invasive cells.

\section{Estimation of ROS and MMP}

The mitochondrial membrane potential (MMP) and reactive oxygen species (ROS) quantification was done by DiOC6 $(1 \mu \mathrm{mol} / \mathrm{l})$ and dihydrofluorescein diacetate $(10 \mu \mathrm{M})$, respectively, by flow cytometrically and are presented in the form of bar diagrams. The procedure was repeated three times.

\section{Western blotting}

After washing the camelliol C-treated cervical cancer cells with PBS, the cells were lysed using RIPA buffer and centrifuged to collect the supernatant. BCA assay was utilised to determine the protein content of the cell extracts. Subsequently, 
$20 \mu \mathrm{g}$ of protein was subjected to separation on SDS-PAGE and then shifted to PVDF. Next, non-fat milk was used for blocking, and then the membranes were incubated with primary antibodies for $3.5 \mathrm{~h}$ at $37^{\circ} \mathrm{C}$ and then with secondary antibody at $25^{\circ} \mathrm{C}$. Finally, an ECL-chemiluminescent kit was used to observe the protein bands of interest.

\section{Statistical analysis}

The experiments were performed in triplicate and expressed as mean \pm SD. For statistical analysis, one-way ANOVA followed by Turkeys test were performed using SPSS software. The experiments were performed in triplicate and $p<0.05$ was taken as a statistically significant difference.

\section{Results}

Camelliol $C$ suppresses the viability of cervical cancer cells

Camelliol $\mathrm{C}$ exerts inhibitory effects on the viability of the cervical cancer cells, as ascertained by MTT assay. The normal NCEC and four different types of cervical cancer cell lines (Caski, HeLa, C33A, and $\mathrm{siHa}$ ) were treated with $0-320 \mu \mathrm{M}$ concentrations of camelliol C for $24 \mathrm{~h}$, and the proliferation rates of cells were determined. It was found that the viability of all the cervical cancer cells decreased proportionally with the increasing doses of camelliol $C$ with $I C_{50}$ ranging from 10 to $20 \mu \mathrm{M}$ (Table I, Figure $1 \mathrm{~A}$ ). Surprisingly, the effects of camelliol $\mathrm{C}$ on the normal cells were less severe, as shown by the $\mathrm{IC}_{50}$ of around $90 \mu \mathrm{M}$ (Figure $1 \mathrm{~B}$ ). Because the lowest of $\mathrm{IC}_{50}$ of $10 \mu \mathrm{M}$ was observed against the HeLa cells, this cell line was selected for further investigation.

\section{Camelliol C promotes ROS-mediated cell} death in cervical cancer cells

The results of fluorescence microscopy of DAPI stained HeLa cells revealed that the anti-prolif-

A

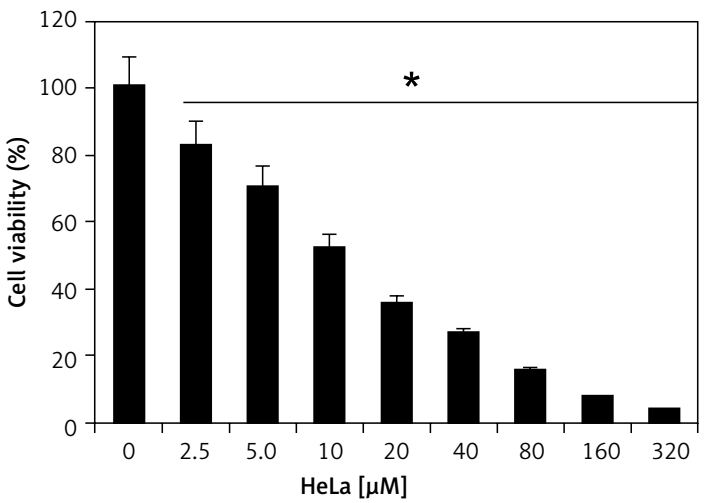

Table I. MTT assay showing the antiproliferative effects of camelliol $C$ expressed as $I C_{50}$ values

\begin{tabular}{|lcc|}
\hline No. & Cell line & IC $_{50}[\mu \mathrm{M}]$ \\
\hline 1 & Caski & 15 \\
\hline 2 & HeLa & 10 \\
\hline 3 & C33A & 15 \\
\hline 4 & siHa & 20 \\
\hline 5 & NCEC & 90 \\
\hline
\end{tabular}

erative effects of camelliol $C$ on the proliferation of human cervical cancer cells were mainly due to the initiation of apoptosis in the HeLa cervical cancer cells, as shown by the increase in the nuclear fragmentation of the HeLa cells (Figure 2 A). The extent of apoptosis induced by camelliol $C$ was determined by annexin V/PI staining. The percentage of apoptosis increased from $6.5 \%$ to $24.2 \%$ from control to $20 \mu \mathrm{M}$ camelliol C (Figure $2 \mathrm{~B}$ ). That camelliol $C$ induces apoptosis was also further validated by investigating the effects of the expression of the apoptosis-related proteins. The expression of cytochrome $\mathrm{c}$ and Bax increased while the protein levels of Bcl-2 showed a dose dependent decrease. However, Bid expression remained almost unaltered at all concentrations of camelliol C (Figure $2 \mathrm{C}$ ). The results showed a remarkable increase in the cleavage of caspsase- 3 and -9 as well as PARP in camelliol C-treated HeLa cells. The expression of caspase- 8 remained more or less constant (Figure 2 D). The results also showed that camelliol $C$ increased ROS levels and concomitantly decreased MMP levels in HeLa cells (Figures 3 A, B) suggesting that camelliol imitates ROS mediated cell death in HeLa cells.

\section{Camelliol C promotes G2/M arrest of cervical cancer cells}

Flow cytometry analysis of the camelliol C-treated cells showed that inhibition of the

B

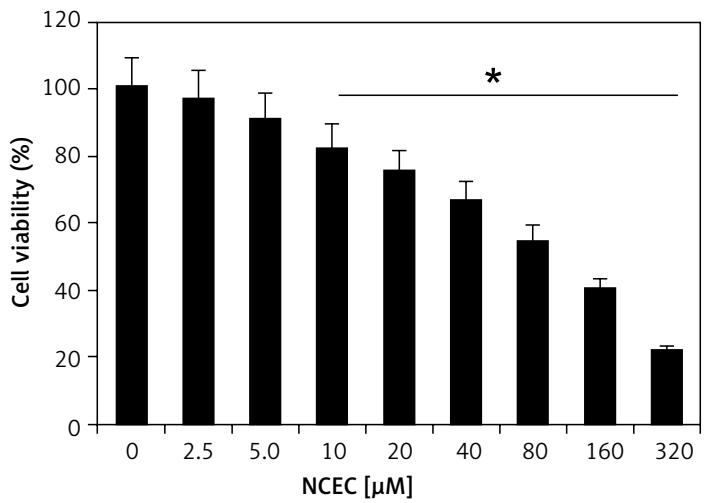

Figure 1. Camelliol $C$ inhibits the proliferation of cervical cancer cells. The effect of camelliol $C$ on HeLa cervical cancer cells (A) and normal NCEC cells (B). The experiments were performed in triplicate and are expressed as mean $\pm \mathrm{SD}\left({ }^{*} p<0.05\right)$ 


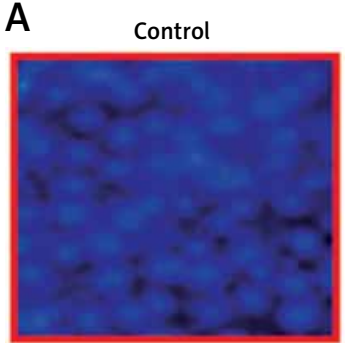

$10 \mu \mathrm{M}$
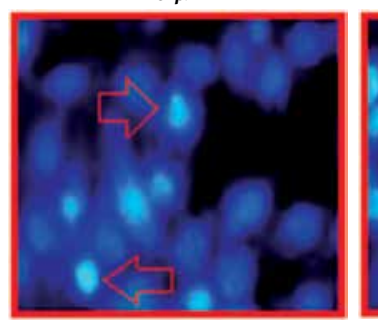

C
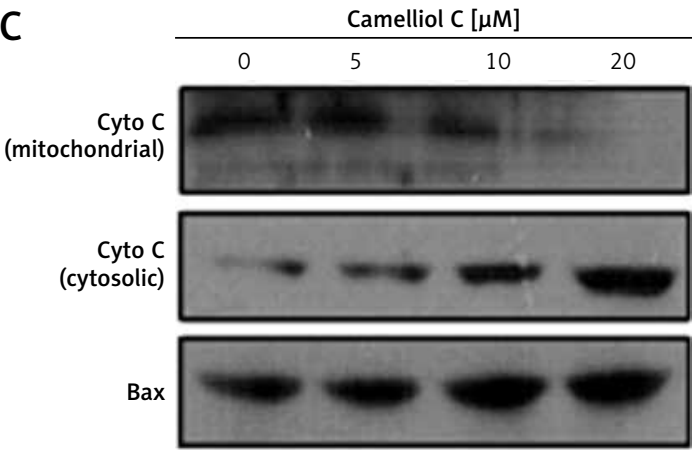

Bcl-2

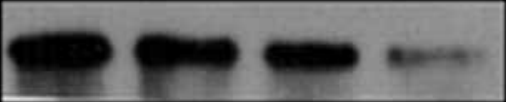

Bid

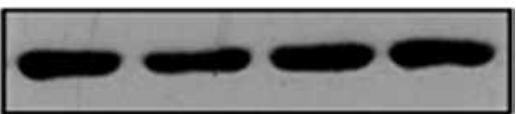

Actin

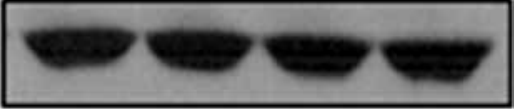

B

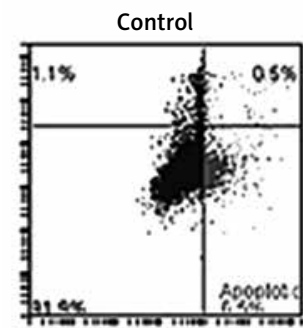

$\bar{\alpha}$
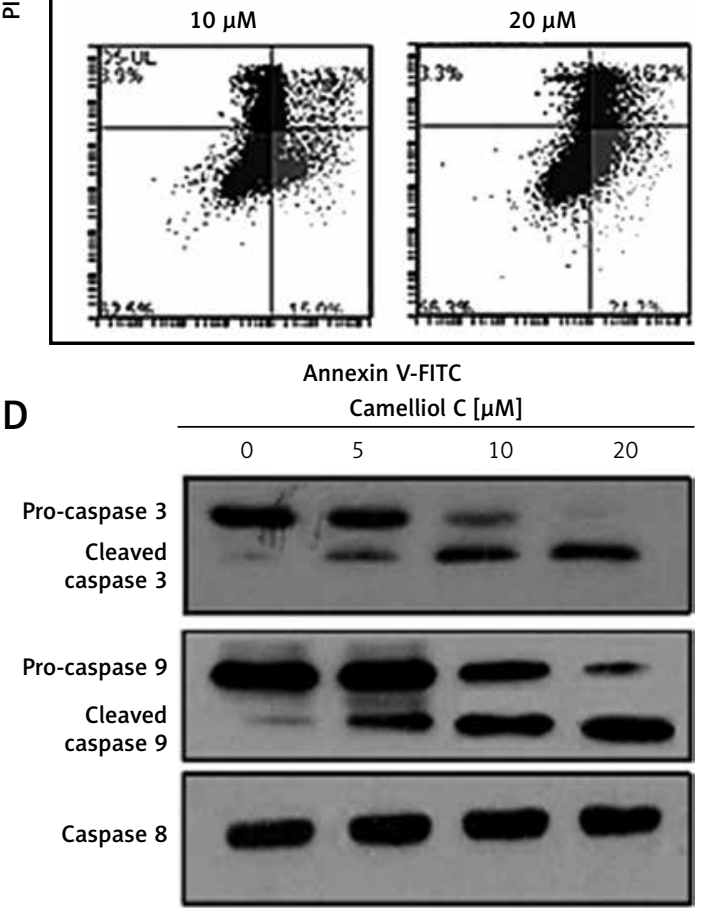

Caspase 8

PARP

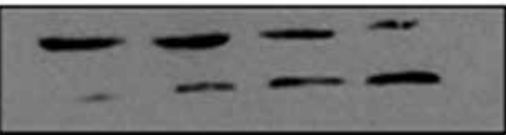

Cleaved PARP

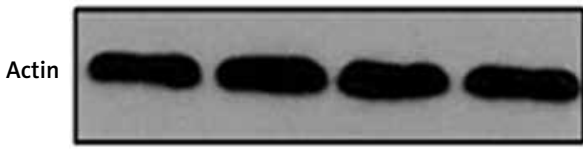

Figure 2. Camelliol C induces apoptosis in cervical cancer cells. DAPI (A) and annexin V/PI (B) staining of camelliol C-treated HeLa cells, showing induction of apoptosis. Western blots of Cyto C, Bax, Bcl-2, Bid (C), and caspase-3, -9 and -8 and PARP (D). The experiments were performed in triplicate

A

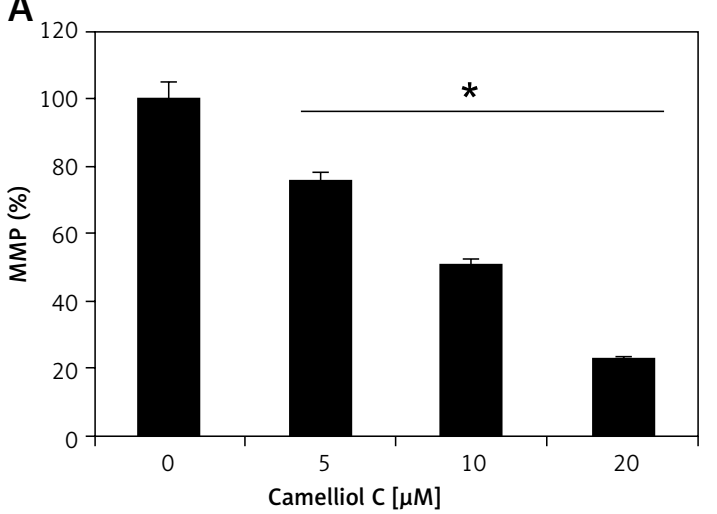

B

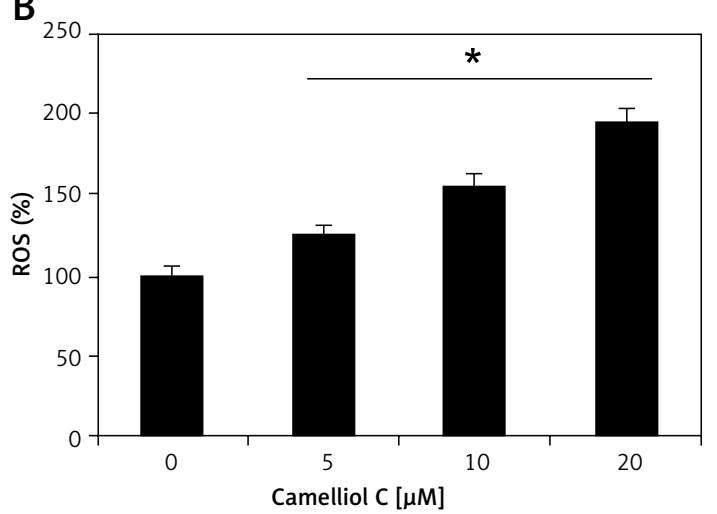

Figure 3. Camelliol C increases ROS and decreases MMP levels in cervical cancer cells. Effect of camelliol C on MMP (A) and ROS (B) levels in HeLa cells at indicated concentrations. The experiments were performed in triplicate and are expressed as mean \pm SD $\left({ }^{*} p<0.05\right)$ 
HeLa cell proliferation was not only because of the apoptosis but also because of the G2/M cell cycle arrest. This was evident from the increase in the percentage of the $\mathrm{G} 2 / \mathrm{M}$ phase cells with increased dosage of camelliol $C$ (Figure $4 \mathrm{~A}$ ). The initiation of the $\mathrm{G} 2 / \mathrm{M}$ arrest was also linked with alteration in the expression of certain proteins, as revealed by western blotting. The phosphorylation of $\mathrm{Cdc} 25 \mathrm{c}$ and cdc2 was considerably decreased. Additionally, the protein levels of cyclin B1 were also depleted (Figure 4 C). The expression of p27 and p53 showed no alteration, and that of p21 showed a constant increase (Figure $4 \mathrm{D}$ ).
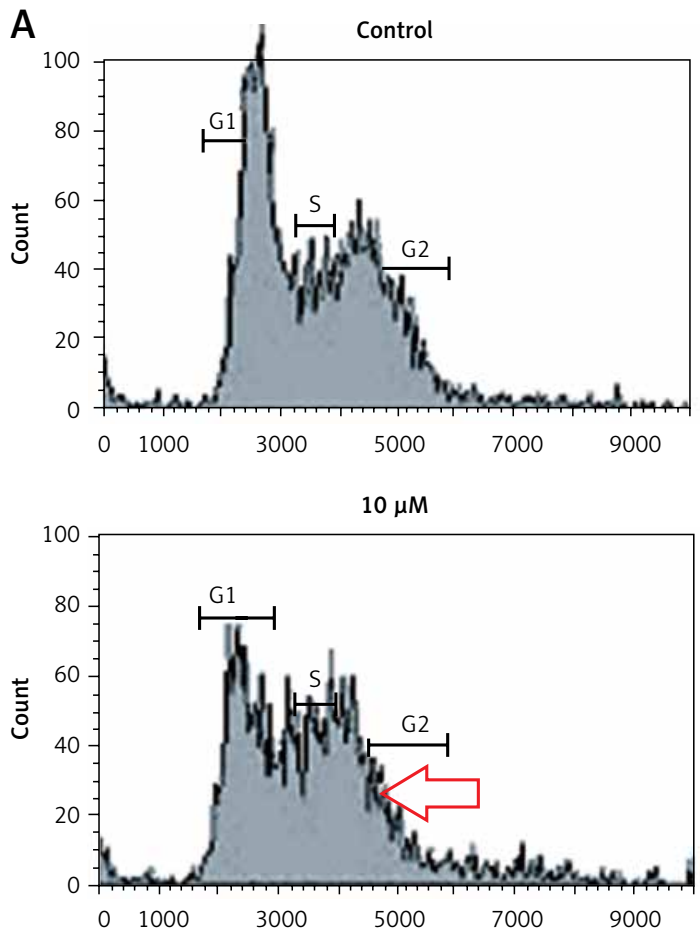

B

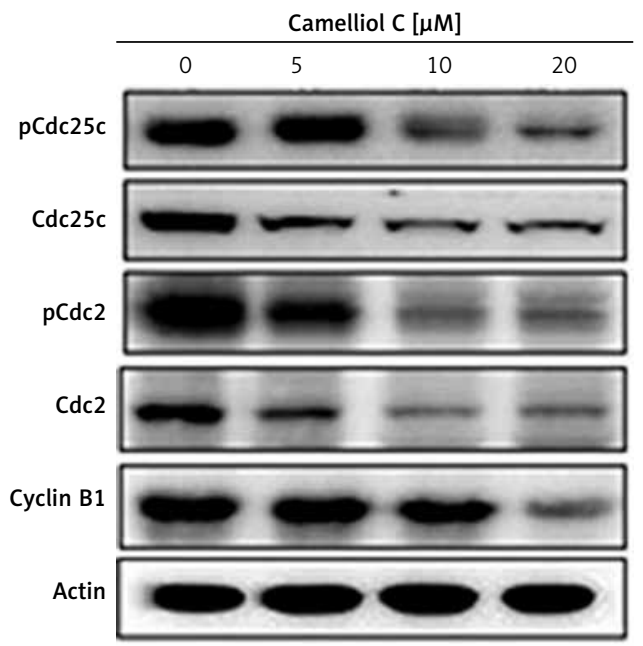

\section{Camelliol C blocks PI3K/AKT signalling}

The impact of camelliol $C$ was also evaluated on the PI3K/AKT signalling pathway. It was found that the protein levels of p-AKT and p-PI3K declined significantly, and in a concentration-dependent manner (Figure 5). Nonetheless, there was no apparent effect on the total PI3K and AKT.

\section{Camelliol $\mathrm{C}$ suppresses migration and invasion of HeLa cells}

Determination of the effects of camelliol $C$ on the migration and invasion of the human HELA cervical cancer cells was done by transwell as-
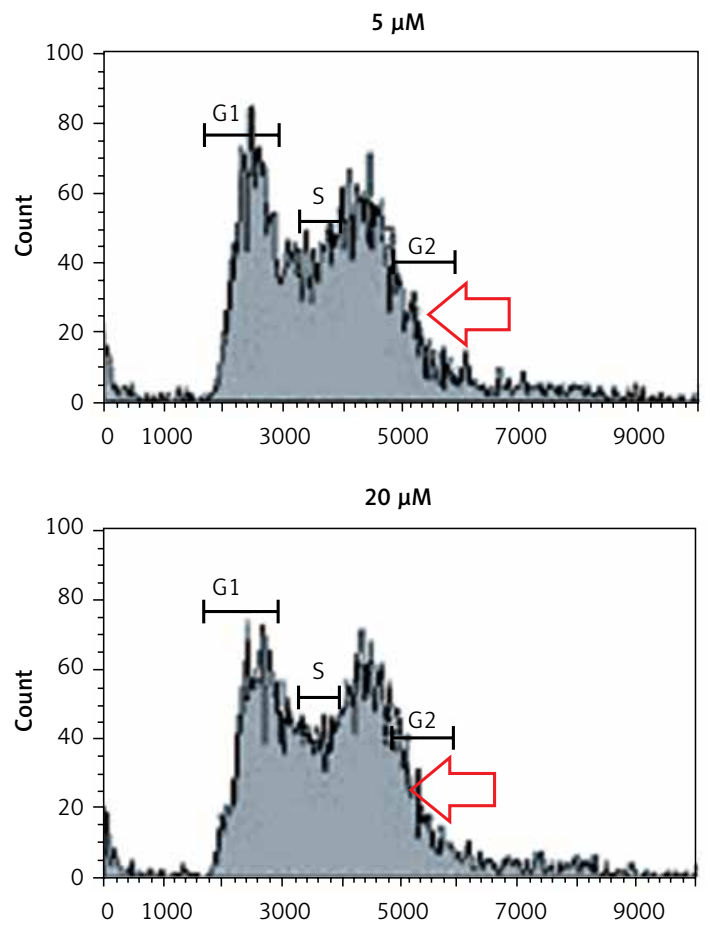

C

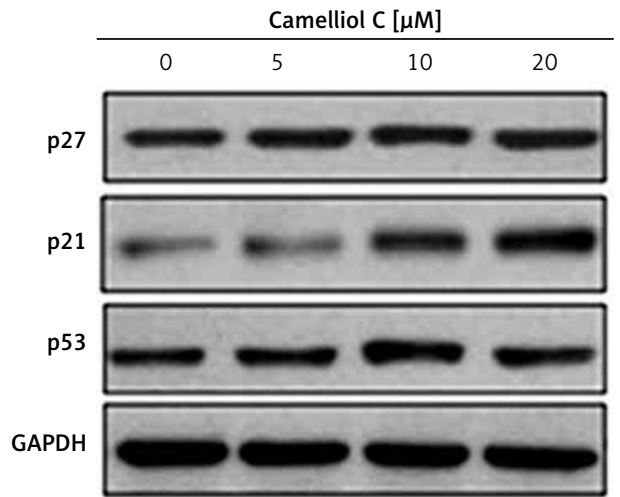

Figure 4. Camelliol C induces G2/M cell cycle arrest in cervical cancer cells. A - Flow cytometry showing the effect of camelliol C on the cell cycle distribution of HeLa cells. B - Western blots showing the effect of camelliol C on Cdc25 $\mathrm{c}$ and $\mathrm{Cdc} 2$ phosphorylation. $\mathrm{C}$ - Western blots showing the effect of camelliol C on p27, p21, and p53 expression. The experiments were performed in triplicate 
A

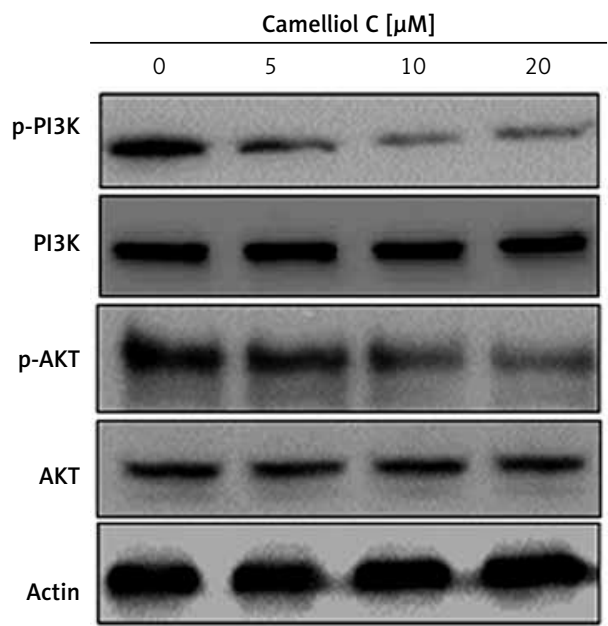

B

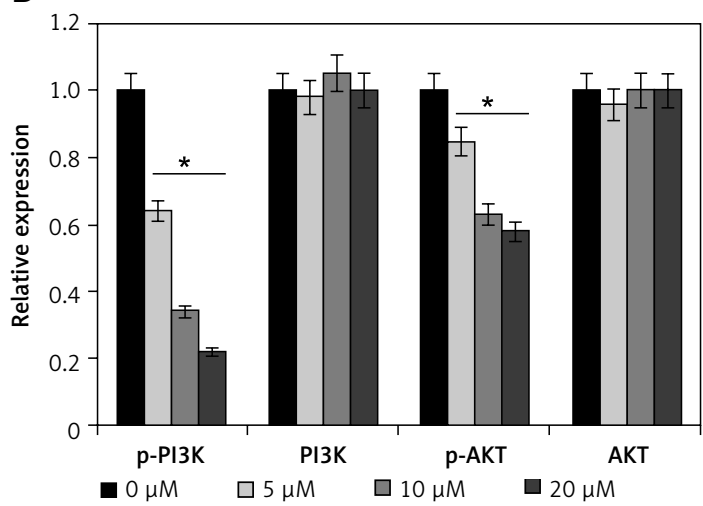

Figure 5. Effect of camelliol $\mathrm{C}$ on the phosphorylation of PI3K and AKT as depicted by western blotting. The experiments were performed in triplicate

says. The results revealed that the camelliol C suppressed the migration of the HELA cell concentration dependently (Figure 6 A). The effects of camelliol $C$ were also determined on HELA cell invasion, and the results were similar to those for cell migration (Figure 6 B).

\section{Discussion}

Plants have to adapt to harsh and changing environmental conditions, and over the course of evolution they have learned to defend themselves by synthesising a wide array of molecules, including triterpenoids. Triterpenoids constitute a large and diverse group of plant-derived compounds with enormous pharmacological potential [12]. They are ubiquitously found across the kingdom Plantae. These plant-derived metabolites have a wide array of bioactivities in plants, such as anticancer and anti-microbial [13]. Accordingly, active research is ongoing to examine the anticancer

\section{A}
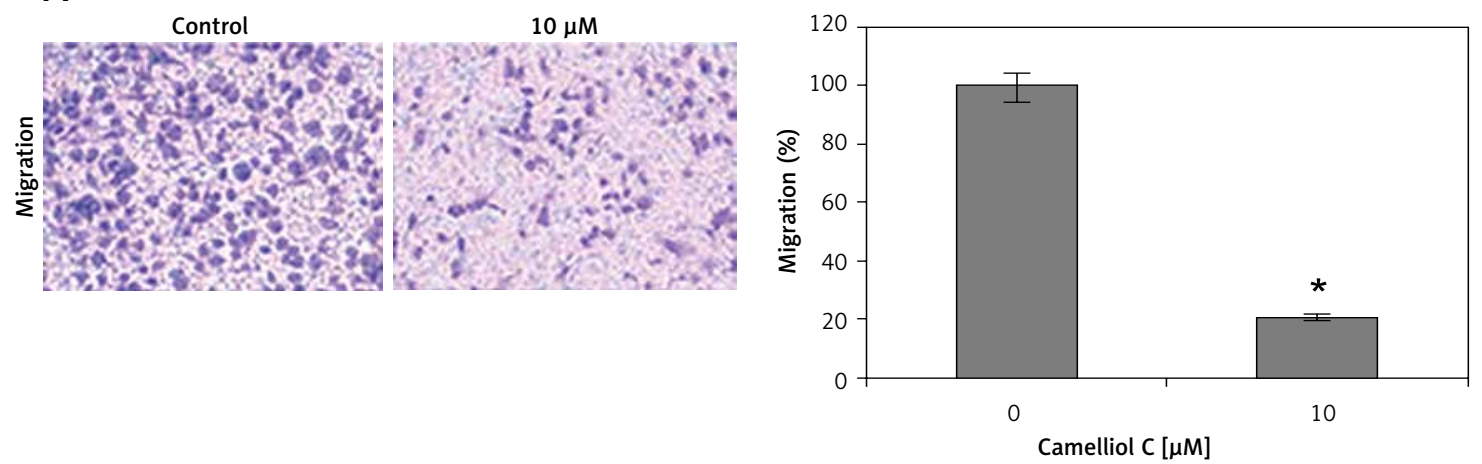

B
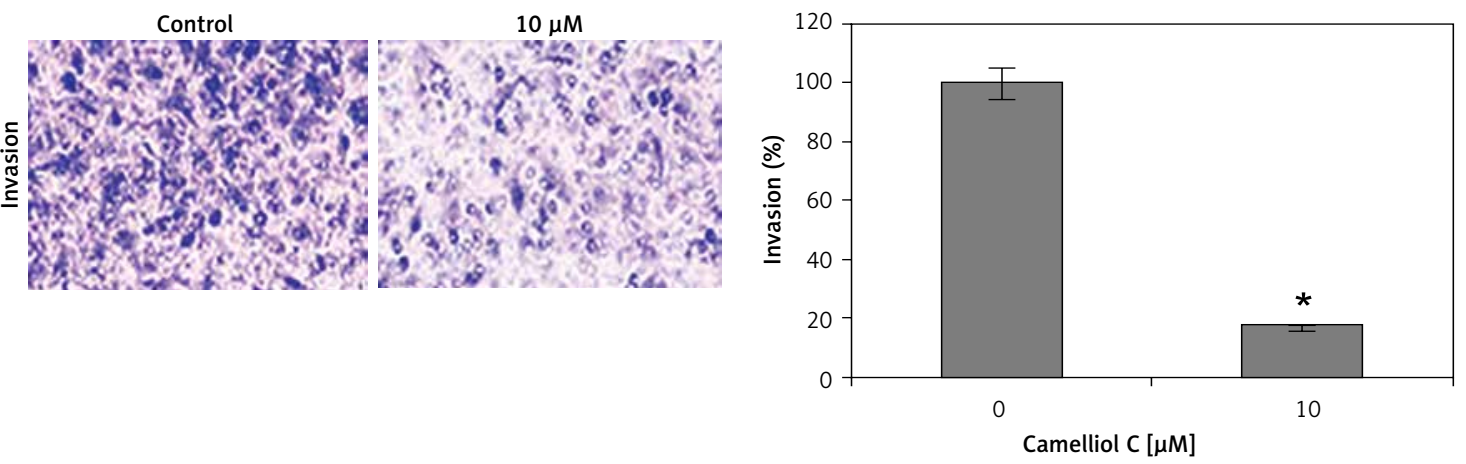

Figure 6. Camelliol $C$ inhibits the migration and invasion of cervical cancer cells. Effect of camelliol $C$ on the migration (A) and the invasion (B) of HeLa cells. The experiments were performed in triplicate and are expressed as mean \pm SD $\left({ }^{*} p<0.05\right)$ 
effects of triterpenoids against different human cancers. This study was undertaken to evaluate the anticancer effects of camelliol C, a naturally occurring triterpenoid of plant origin against human cervical cancer cells. The cell proliferation assay showed significant inhibition of cervical cancer cell growth upon camelliol $C$ treatment. Previous studies have shown that triterpenoids have the potential to trigger apoptosis in different cancer cells [14]. More precisely, the plant-derived triterpenoid friedelin has been shown to suppress the growth of lung cancer cells via induction of apoptosis [15]. The expression of cleaved caspase- 3 and -9 , as well as that of cleaved PARP, was remarkably increased. Additionally, the Bax/ $\mathrm{Bcl}-2$ ratio was also increased, which is an important indicator of apoptosis [16]. Apoptosis plays a key role in eliminating the defective cells, and thus drugs that promote apoptosis are currently being studied extensively [17]. We also investigated the effects of camelliol $C$ on the HeLa cell distribution and found that camelliol $C$ induces G2/M arrest of HeLa cells and also blocked the phosphorylation of CCdc2 and CCdc25c. These findings may explain for the low $I C_{50}$ of camelliol $C$ against the HeLa cells. Several triterpenoids have also been shown to induce cell cycle arrest of cancer cells, which is in agreement with the present study [18]. This study also examined the effects of camelliol C on migration and invasion of the HeLa cells. It was found that camelliol $C$ suppressed the migration and invasion of the HeLa cells. These findings are in agreement with a previous study in which a triterpenoid, ursolic acid, was found to suppress the migration and invasion of cancer cells [18]. Aberrant activation of the PI3K-Akt pathway has been shown to be involved in the development and progression of different cancer types. PI3K was first identified as an enzymatic activity associated with the Rous sarcoma pp60v-src protein and the polyoma middle $T$ antigen, which is essential for the transforming activity of these oncogenes, and Akt was also found to be a viral oncogene [19, 20]. Studies have shown that PI3K/AKT may prove to be an optimal target for anticancer drugs [21]. Owing to the importance of this pathway, drugs targeted to inhibit this pathway may prove essential in the management of this pathway [19, 22]. Herein, we observed that camelliol $C$ blocks the both the PI3K/AKT signalling pathway. Hence, more studies are required to establish camelliol $C$ as a lead molecule for the development of chemotherapy for cervical cancer. Although this study evaluated the anticancer effects of camelliol C under in vitro conditions, this study will definitely pave the way for its in vivo evaluation.

In conclusion, the results of the present study show that camelliol $C$ inhibited the growth of human cervical cancer cells via induction of apop- tosis and G2/M cell cycle arrest. Camelliol C also suppresses the migration and invasion of cervical cancer via blocking the PI3K/AKT pathway. These findings point towards the potential of camelliol $C$ as a lead molecule for the treatment of cervical cancer.

\section{Acknowledgments}

This subject was funded by a science and technology project of Dongying Science and Technology Bureau (No. 2018-079).

\section{Conflict of interest}

The authors declare no conflict of interest.

\section{References}

1. Schiffman M. Cervical cancer screening: epidemiology as the necessary but not sufficient basis of public health practice. Prev Med 2017; 8: 3-6.

2. Arbyn M, Castle PE. Offering self-sampling kits for HPV testing to reach women who do not attend in the regular cervical cancer screening program. Cancer Epidemiol Biomarkers Prev 2015; 1: 1414-7.

3. Di Felice E, Caroli S, Paterlini L, Campari C, Prandi S, Rossi PG. Cervical cancer epidemiology in foreign women in Northern Italy: role of human papillomavirus prevalence in country of origin. Euron J Cancer Prev 2015; 24: 223-30.

4. Motoki Y, Mizushima S, Taguri M, et al. Increasing trends in cervical cancer mortality among young Japanese women below the age of 50 years: an analysis using the Kanagawa population-based Cancer Registry, 19752012. Cancer Epidemiol 2015; 39: 700-6.

5. Piver MS, Rutledge F, Smith JP. Five classes of extended hysterectomy for women with cervical cancer. Obstetrics Gynecol 1974; 44: 265-72.

6. Prakash CV, Prakash I. Isolation and structural characterization of Lupane triterpenes from Polypodium vulgare. Res J Pharm Sci 2012; 1: 23-7.

7. Ourisson G, Albrecht P. Hopanoids. 1. Geohopanoids - the most abundant natural products on earth. Acc Chem Res 1992; 25: 398-402.

8. Thimmappa R, Geisler K, Louveau T, O’Maille P, Osbourn A. Triterpene biosynthesis in plants. Ann Rev Plant Biol 2014; 65: 225-57.

9. Kommera H, Kaluđerović GN, Kalbitz J, Dräger B, Paschke R. Small structural changes of pentacyclic lupane type triterpenoid derivatives lead to significant differences in their anticancer properties. Eur J Med Chem 2010; 45: 3346-53.

10. Kolesnikova MD, Wilson WK, Lynch DA, Obermeyer AC, Matsuda SP. Arabidopsis camelliol C synthase evolved from enzymes that make pentacycles. Org Lett 2007; 9 : 5223-6.

11. Chiang LC, Ng LT, Lin IC, Kuo PL, Lin CC. Anti-proliferative effect of apigenin and its apoptotic induction in human Hep G2 cells. Cancer Lett 2006; 237: 207-14.

12. Dutta S, Mahalanobish S, Saha S, Ghosh S, Sil PC. Natural products: an upcoming therapeutic approach to cancer. Food Chem Toxicol 2019; 128: 240-55.

13. Yadav VR, Prasad S, Sung B, Kannappan R, Aggarwal BB. Targeting inflammatory pathways by triterpenoids for prevention and treatment of cancer. Toxins 2010; 2: 2428-66. 
14. Petronelli A, Pannitteri G, Testa U. Triterpenoids as new promising anticancer drugs. Anticancer Drugs 2009; 20 : 880-92.

15. Subash-Babu P, Li DK, Alshatwi AA. In vitro cytotoxic potential of friedelin in human MCF-7 breast cancer cell: regulate early expression of Cdkn2a and pRb1, neutralize mdm2-p53 amalgamation and functional stabilization of p53. Exp Toxicol Pathol 2017; 69: 630-6.

16. Lowe SW, Lin AW. Apoptosis in cancer. Carcinogenesis 2000; 21: 485-95.

17. Fisher DE. Apoptosis in cancer therapy: crossing the threshold. Cell 1994; 78: 539-42.

18. Yeh CT, Wu CH, Yen GC. Ursolic acid, a naturally occurring triterpenoid, suppresses migration and invasion of human breast cancer cells by modulating c-Jun $\mathrm{N}$-terminal kinase, Akt and mammalian target of rapamycin signaling. Mol Nutrition Food Res 2010; 54: 1285-95.

19. Asati V, Mahapatra DK, Bharti SK. PI3K/Akt/mTOR and Ras/Raf/MEK/ERK signaling pathways inhibitors as anticancer agents: structural and pharmacological perspectives. Eur J Med Chem 2016; 109: 314-41.

20. Hennessy BT, Smith DL, Ram PT, Lu Y, Mills GB. Exploiting the PI3K/AKT pathway for cancer drug discovery. Nature Rev Drug Discov 2005; 4: 988-1004.

21. Luo J, Manning BD, Cantley LC. Targeting the PI3K-Akt pathway in human cancer: rationale and promise. Cancer Cell 2003; 4: 257-62.

22. Zhihong Z, Rubin C, Liping L, et al. MicroRNA-1179 regulates proliferation and chemosensitivity of human ovarian cancer cells by targeting the PTEN-mediated PI3K/AKT signaling pathway. Arch Med Sci 2019. doi:10.5114/aoms.2019.86798. 